\title{
SURFACTANT FOAM SELECTION FOR ENHANCED LIGHT NON AQUEOUS PHASE LIQUIDS (LNAPL) RECOVERY IN CONTAMINATED AQUIFERS
}

Mélanie Longpré-Girard ${ }^{\mathrm{a}}$, Richard Martel ${ }^{\mathrm{a}^{*}}$, Thomas Robert ${ }^{\mathrm{a}}$, René Lefebvre ${ }^{\mathrm{a}}$, Jean-Marc Lauzon $^{\mathrm{b}}$, Neil Thomson ${ }^{\mathrm{c}}$

${ }^{a}$ Centre Eau Terre Environnement, Institut national de la recherche scientifique (INRS), 490 rue de la Couronne, Québec, Québec, Canada, G1K 9A9

${ }^{\mathrm{b}}$ TechnoRem Inc., 4701 Rue Louis B Mayer, Laval, Québec, Canada, H7P 6G5

${ }^{c}$ Civil and Environmental Engineering, University of Waterloo, 200 University avenue West, Waterloo, Ontario, Canada, N2L 3G1

*Corresponding author: richard.martel@ete.inrs.ca.

\section{Acknowledgements}

Funding for this study was provided by a NSERC-CRD grant (412730-11) in partnership with TechnoRem and a NSERC-discovery grant (326975-2011) held by Richard Martel. The authors would like to gratefully acknowledge the donation of surfactant samples by Stepan, the help of Mr. Luc Trépanier form INRS in designing and installing the foam injection system,of Mr. Marco Boutin from INRS for figures and tables improvements, and of Dr. Clément Portois for internal review. We acknowledge reviewers (M. Babs Oyeneyin from Robert Gordon University and anonymous) for comments and suggested corrections.

\section{Abstract}

Foam is promising for the remediation of Non Aqueous Phase Liquids (NAPL) source zones, however, the production of foam and its behavior in porous media are poorly understood. A methodology for the selection of surfactants suitable for foam production applied to NAPL remediation was developed. Two critera were initially used for surfactant selection: foamability as evaluated by the Ross Miles test and interfacial tension reduction measured with the Pendant Drop method. Three promising surfactants were identified and used in sand column tests : Genapol LRO because it produced the highest foam height in the Ross Miles test, Ammonyx Lo which exhibited the lowest interfacial tension with $p$-xylene and had the second highest foam height, and Tomadol 900 because it showed intermediate results in both tests. Viscosity was found to be proportional with foamability. Genapol LRO produced a foam so viscous that it destabilized by the end of the experiment. Ammonyx Lo produced a less viscous 
foam but with a stable front. Tomadol 900 produced an unstable foam with poor viscosity. Results from column tests gave indications of optimal conditions needed to produce a stable and viscous foam front.

\section{Introduction}

Many studies on surfactant foam have been carried out in the petroleum industry for their application to enhanced oil recovery (EOR) in deep oil reservoirs (Li et al., 2012a; Farajzadeh et al., 2012; Shallcross et al., 1990; Simjoo et al., 2012; Nguyen et al., 2007). However, environmental applications for non-aqueous phase liquid (NAPL) source zone remediation under field conditions are quite different from EOR: NAPL-contaminated shallow aquifers are mostly unconsolidated porous materials, a low injection pressure must be used to prevent soil heaving and the natural groundwater present in the pores is not saline. The selection of foam for environmental remediation (ER) differs from the one for enhanced oil recovery (EOR) for two main reasons: (1) the low toxicity and high biodegradability criteria used to screen surfactants selected for ER.; and (2) the fact that the addition of salt for ER applications is not always desirable, whereas in EOR it is the common practice to optimise the foam formulation with sodium salt to reach the lowest interfacial tension (IFT) (Lake, 1989). One issue with salt in ER is related to the difficulty of maintaining the optimal salinity required for low IFT in (fresh) groundwater of aquifers during surfactant injection. Another issue is that salt has to be removed from the wastewater produced during ER, contributing to an increase in effluent treatment costs. In EOR, saline water present in the petroleum reservoir helps to maintain the optimised conditions to maintain low IFT.

A few laboratory studies have been carried out to assess foam behavior in porous media for their application to the ER of shallow contaminated soils (Mulligan and Eftekhari, 2003; Couto et al., 2009, Tanzil et al. 2002a). The application of foams to the ER of Light Non-Aqueous Phase Liquids (LNAPL) is studied here, whereas some of the previous work considered Dense NonAqueous Phase Liquids (DNAPL), such as Trichloroethylene (TCE), as the type of contaminant to be removed (Jeong and Corapcioglu, 2000, 2003, 2005; Rothmel et al., 1998; Pennell et al., 1996). For a DNAPL, mobilization has to be avoided to prevent the sinking which would worsen site conditions. Some field-scale tests of foam injection in shallow soils were also conducted (Hirasaki et al., 2000). 
The work reported in this paper was undertaken in the context of an application of foam to remediate a LNAPL-contaminated aquifer. The objective of the study was to develop a methodology for: (1) the selection of surfactants suitable for foam production applied to $p$-xylene remediation, (2) the ex-situ production of foam, and (3) characterization of the behavior of foam injected in a water-saturated sand column. So, the surfactant selection method proposed here does not use salinity scan with the surfactant and the contaminant in test tubes to find the optimal salinity as proposed by Hirasaki et al., 2000.

\subsection{Enhanced NAPL recovery mechanisms with surfactants and foams}

Foam flow through porous media is defined by Hirasaki (1989) as a "dispersion of gas in liquid such that the liquid phase is continuous (i.e. connected) and at least some part of the gas phase is made discontinuous by thin liquid films called lamellae". Foam has non-Newtonian and shearthinning properties (Hirasaki and Lawson, 1985; Falls et al., 1989), which makes foam an alternative to the use of polymers for mobility control (Martel et al., 1998; Martel et al., 2004; Robert et al., 2006). Also, the presence of air in foam reduces significantly the amount of surfactant needed to sweep a given aquifer volume, compared to the injection an aqueous surfactant solution. Thus, when compared with surfactant solutions, the use of foam can lower the mass of surfactant needed and even replace the use of polymers. Thus, if the efficiency of foam for NAPL source zone remediation can be demonstrated, foam could represent an economic alternative to other NAPL source zone flushing technologies.

Mobilization (pure phase displacement driven by capillary number), dissolution (advective solute transport of organic phase in water) and volatilization (contaminant transfer into gas phase) are the three recovery mechanisms taking place during foam injection for DNAPL remediation (Mulligan and Eftekhari, 2003). When a LNAPL-contaminated aquifer is treated, volatilization may be significant if a large volume of air is circulated via foam injection in the porous medium (Longpré-Girard et al., 2016). However, mobilization could be the main recovery mechanism if a stable foam front pushing on the LNAPL is created. Interfacial tension is a key parameter for the evaluation of potential NAPL dissolution and mobilization. In order to maximize the capillary number for mobilization, the interfacial tension between the NAPL and surfactant solution has to be minimized. To minimize costs, low concentrations of surfactant are used for foam production, which means that enhanced dissolution would be low. LNAPL recovery with volatilization would also be small compared to mobilization because of the limited transfer from the NAPL phase to 
the air phase. NAPL may be mobilized due to the increase of the capillary number $\left(\mathrm{N}_{c}\right)$, which is defined as follows (Pennell et al., 1996):

$$
N_{c}=\frac{\mu q}{\sigma \cos \theta}
$$

The increase in viscous forces is achieved by increasing the injected fluid viscosity $(\mu)$ and its flux (or velocity) $(q)$ in the porous media, whereas a decrease in capillary forces is possible via a reduction of interfacial tension $(\sigma)$ by the presence of a surfactant. The wettability is represented by the contact angle $(\theta)$. Therefore, maximizing $N_{c}$ increases the possibility to displace a contaminant with foam. Replacing water by foam as the displacing fluid in porous media favors NAPL mobilization because, compared to water, it increases viscosity and decreases interfacial tension by at least one order of magnitude (Hirazaki and Lawson, 1985).

\subsection{Foam properties}

Two properties were considered in this study to characterize foam-forming surfactants: foamability and foam quality. Foamability correspond to the ability of the surfactant to create bubble and its ability to maintain this state over the time. Foam quality correspond to gas fractional flow used to generate foam. Foam has a dynamic nature, its properties evolving significantly through time. Furthermore, the same surfactant can produce foam with different properties depending on the production method. Consequently, in order to compare different surfactant candidates for foam production, the same foam production method and the same measurement conditions need to be used.

\section{Methodology}

\subsection{Surfactant selection methodology}

First, p-xylene was selected as the model LNAPL representative of gasoline: density of 0.8611 $\mathrm{kg} / \mathrm{m}^{3}$ (lighter than water), viscosity of $0.644 \mathrm{mPa} \cdot \mathrm{s}$, vapor pressure of $0.0086 \mathrm{~atm}$ (all these properties are at $20^{\circ} \mathrm{C}$; Johnson et al., 1990; Mercer and Cohen 1990). Also, p-xylene is an aromatic hydrocarbon that has 8 carbons $\left(\mathrm{C}_{8}\right)$ is a good average of gasoline which is a mixture of tens of hydrocarbons (alkanes linear or branched, alcenes and aromatics) having a number 
of carbons ranging from $\mathrm{C}_{5}-\mathrm{C}_{10}$. Finally, on a ternary phase diagram, looking at the miscibility of $\mathrm{p}$-xylene or gasoline in water in the presence of surfactant, both show the same miscibility zone.

Three criteria were considered to select the most suitable surfactant for foam production: biodegradability, foamability and interfacial tension. Foamability was measured with the Ross Miles Test (ASTM D1173). Interfacial tensions between different concentrations of surfactant aqueous solutions $(0.01 \%, 0,1 \%$ and $1 \%$ mass/mass) and $p$-xylene were measured by the pendant drop method (Woodward, 2000) and the best candidates with the lowest interfacial tension with the contaminant were considered for further investigation.

Table 1 presents the list of all surfactants tested including their biodegradability and critical micellar concentrations (CMC). All surfactants were biodegradable, except Triton X-100 that was tested for comparison purposes. The surfactant concentrations tested are above their CMC indicating that part of the p-xylene can be solubilized. The foam approach (criteria to select the best foam for this application) is based on mobilization, so the solubilization component was not considered in the surfactant selection. However, the foam stability is maximum at surfactant concentrations above 10 times their CMC (Lee et al., 1991, 1990, Mannhardt et al., 2000, Portois, 2018) so, the surfactant tested at $1 \%$ were all above this criteria whereas at $0.1 \%$ in concentrations they may be below or above the10xCMC criteria as shown in the last two columns of Table 1. 
Table 1 - List of tested surfactants.

\begin{tabular}{|c|c|c|c|c|c|c|c|c|c|c|}
\hline & \multirow{2}{*}{ Surfactant } & \multirow{2}{*}{ Chemical Name } & \multirow{2}{*}{$\begin{array}{c}\text { CAS } \\
\text { number }\end{array}$} & \multirow{2}{*}{ Type } & \multirow{2}{*}{$\begin{array}{c}\text { Active } \\
\text { Matter } \\
(\% \text { w/w })^{\star *}\end{array}$} & \multirow{2}{*}{ Supplier } & \multirow{2}{*}{$\begin{array}{l}\text { Biodegrada } \\
\text { bility* }\end{array}$} & \multirow{2}{*}{$\begin{array}{c}\text { CMC } \\
\text { (\%-mass)* }\end{array}$} & \multicolumn{2}{|c|}{$\begin{array}{l}\text { Nbr. of } \\
\mathrm{CMC} \text { at }\end{array}$} \\
\hline & & & & & & & & & $0.1 \%$ & $1 \%$ \\
\hline A & $\begin{array}{l}\text { Genapol } \\
\text { LRO }\end{array}$ & $\begin{array}{l}\text { Sodium alkyl } \\
\text { ether sulfate }\end{array}$ & $\begin{array}{c}\text { 68891- } \\
38-3\end{array}$ & Anionic & 68 & Clariant & Readily & $3.3 \times 10^{-2}$ & 3 & 30 \\
\hline B & $\begin{array}{l}\text { Ammonyx } \\
\text { LO }\end{array}$ & Lauramine oxide & $\begin{array}{l}1643- \\
20-5\end{array}$ & Amphoteric & 31 & Stepan & Readily & $1.1 \times 10^{-3}$ & 91 & 909 \\
\hline C & $\begin{array}{l}\text { Ammonyx } \\
\text { CDO - } \\
\text { Special }\end{array}$ & $\begin{array}{l}\text { Cocamidopropyl } \\
\text { amine } \\
\text { oxide }\end{array}$ & $\begin{array}{l}68155- \\
09-9\end{array}$ & Amphoteric & 33 & Stepan & Readily & ND & - & - \\
\hline D & $\begin{array}{l}\text { Steol } \\
\text { CS330 }\end{array}$ & $\begin{array}{l}\text { Sodium laureth } \\
\text { sulfate }\end{array}$ & $\begin{array}{l}9004- \\
82-4\end{array}$ & Anionic & 28 & Stepan & Readily & $4.5 \times 10^{-2}$ & 2 & 22 \\
\hline$E$ & $\begin{array}{c}\text { Amphosol } \\
\text { CA }\end{array}$ & $\begin{array}{l}\text { Cocamidropropyl } \\
\text { betaine }\end{array}$ & $\begin{array}{c}\text { 61789- } \\
40-0\end{array}$ & Amphoteric & 30 & Stepan & Readily & $6.2 \times 10^{-3}$ & 16 & 159 \\
\hline$F$ & $\begin{array}{l}\text { Chembetai } \\
\text { ne CAS }\end{array}$ & $\begin{array}{l}\text { Cocamidropropyl } \\
\text { hydroxy sultaine }\end{array}$ & $\begin{array}{c}68139- \\
30-0\end{array}$ & Amphoteric & 50 & Chemco & $\begin{array}{c}\text { 96\% (Mouton } \\
\text { et } \\
\text { al., 2009) }\end{array}$ & $2.3 \times 10^{-3}$ & 43 & 434 \\
\hline G & $\begin{array}{c}\text { Biosoft } \\
\text { N1-9 }\end{array}$ & $\begin{array}{l}\text { Ethoxylated } \\
\text { alcohol }\end{array}$ & $\begin{array}{c}34398- \\
01-1\end{array}$ & Nonionic & 100 & Stepan & $80 \%$ & $1.5 \times 10^{-2}$ & 7 & 66 \\
\hline H & $\begin{array}{c}\text { Tomadol } \\
1-7\end{array}$ & $\begin{array}{l}\text { Ethoxylated } \\
\text { alcohol }\end{array}$ & $\begin{array}{c}34398- \\
01-1\end{array}$ & Nonionic & 100 & $\begin{array}{c}\text { Air } \\
\text { Products }\end{array}$ & Readily & $1.0 \times 10^{-2}$ & 10 & 100 \\
\hline I & $\begin{array}{c}\text { Tomadol } \\
900\end{array}$ & $\begin{array}{l}\text { Ethoxylated } \\
\text { alcohol }\end{array}$ & $\begin{array}{c}68439- \\
46-3\end{array}$ & Nonionic & 100 & $\begin{array}{c}\text { Air } \\
\text { Products }\end{array}$ & Readily & $2.5 \times 10^{-2}$ & 4 & 40 \\
\hline J & $\begin{array}{l}\text { Biosoft } \\
\text { N23-6.5 }\end{array}$ & $\begin{array}{l}\text { Ethoxylated } \\
\text { alcohol }\end{array}$ & $\begin{array}{c}66455- \\
14-9\end{array}$ & Nonionic & 100 & Stepan & $80 \%$ & $1.7 \times 10^{-3}$ & 59 & 588 \\
\hline K & $\begin{array}{l}\text { Triton } \\
\mathrm{X}-100\end{array}$ & $\begin{array}{l}\text { Octylphenol } \\
\text { ethylene oxide }\end{array}$ & $\begin{array}{l}9002- \\
93-1\end{array}$ & Nonionic & 100 & $\begin{array}{l}\text { Sigma- } \\
\text { Aldrich }\end{array}$ & Not readily & $1.9 \times 10^{-2}$ & 5 & 53 \\
\hline L & $\begin{array}{c}\text { Biosoft } \\
\text { N91-8 }\end{array}$ & $\begin{array}{l}\text { Ethoxilated } \\
\text { alcohol }\end{array}$ & $\begin{array}{c}68439- \\
46-3\end{array}$ & Nonionic & 100 & Stepan & $80 \%$ & $2.7 \times 10^{-2}$ & 4 & 37 \\
\hline M & $\begin{array}{c}\text { Polysorbat } \\
80\end{array}$ & $\begin{array}{c}\text { Polyoxyethylene } \\
\text { sorbitan } \\
\text { monooleate }\end{array}$ & $\begin{array}{l}9005- \\
65-6\end{array}$ & Nonionic & 89 & Croda & Readily & $1.4 \times 10^{-3}$ & 72 & 717 \\
\hline
\end{tabular}

* According to supplier datasheet or literature, where indicated. ** correspond to \% of all chemicals except water in the surfactant. *** from Lucy and Tsang 2000. ND: not determined by supplier 


\section{Foamability}

The Ross Miles Test (ASTM D1173) quantified both the capacity to produce foam and its stability under standardized conditions. All surfactants were tested at three concentrations: $0.01 \%, 0.1 \%$ and $1 \%$ on a weight basis of surfactants relative to aqueous solution (w/w).A standard apparatus was needed to carry out the Ross Miles Test (Figure 1). This apparatus consisted of a glass receiver and a $200 \mathrm{~mL}$ glass pipet (Wilmad LabGlass, New Jersey). The methodology was as follows: (1) the walls of the receiver were rinsed with distilled water to clean any remaining surfactant; (2) the stopcock at the bottom of the receiver was closed and the walls were rinsed with $50 \mathrm{~mL}$ of the surfactant solution, which remained at the receiver bottom; (3) the pipet was placed on top of the receiver (the receiver height is standardized so the bottom of the pipet was exactly at a $90 \mathrm{~cm}$ height of the $50 \mathrm{~mL}$ line); (4) the pipet stopcock was opened, which allowed the surfactant solution to fall into the $50 \mathrm{~mL}$ of surfactant solution already at the bottom of the receiver; (5) foam was produced by the drops of surfactant solution; (6) when all the solution has run out, a measurement of foam height was taken at $t=0$ minutes and further measurements were taken at 1, 3, 5 and 15 minutes. 


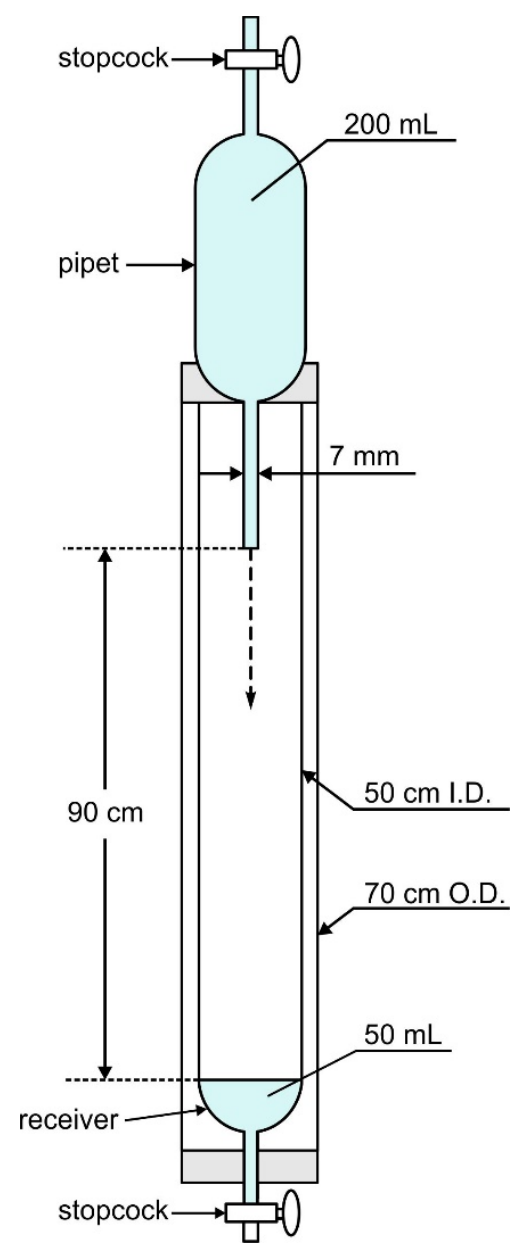

Figure 1 - Apparatus used for the Ross Miles Test.

For the purposes of this study, foamability is considered as the height of foam produced during a Ross Miles Test, as described by Li et al. (2012b). This test involves the use of a fixed volume of surfactant solution that falls in a receiving tube of a certain height into a constant volume of the same surfactant solution. This method had the following advantages: each test was done in a short period of time, it was repeatable and the effect of humidity can be neglected due to the sufficient apparatus height. As reported by Li et al. (2012b), the distance between the top of the foam and the receiver top opening was crucial for the humidity gradient over the foam, which had an effect on foam collapse. When the humidity gradient is low, the evaporation rate is also low and the foam was more stable. Considering that the best foam tested reached a height of $18.6 \mathrm{~cm}$ and the receiver total height of $90 \mathrm{~cm}$, a distance of $71.4 \mathrm{~cm}$ was considered sufficient to have negligible evaporation. However, this technique did not consider the change in foam quality through time, only the foam height. 


\section{Foam Quality}

Foam quality is a parameter used to evaluate the air content of the foam and is defined by the following expression (Chowdiah et al., 1998):

$$
\text { Foam Quality }=\frac{\text { Gas volume }}{\text { Total volume }}
$$

Foam quality was measured at the outlet of the foam production column and at the outlet of the sand column. Foam was recovered in a graduated cylinder of $1 \mathrm{~L}$ to estimate its total volume and the liquid produced after foam breakage. The gas volume is the difference between the total volume minus the liquid volume and the foam quality calculated according to equation above.

\section{Foam viscosity}

Foam being a non-Newtonian fluid, its viscosity is dependant on the shear rate acting on the fluid as it moves through the porous media. A shear thinning non-Newtonian mode is observed when the viscosity of the fluid decreases when the shear rate increases. Chauveteau and Zaitoun (1981) present the equation relating the shear rate $\mathrm{Y}\left(\mathrm{s}^{-1}\right)$ to porosity $\theta(-)$, permeability $\mathrm{k}$ $\left(\mathrm{m}^{2}\right)$ and fluid mean velocity $\mathrm{v}_{\mathrm{rm}}\left(\mathrm{m} \cdot \mathrm{s}^{-1}\right)$ :

$$
\gamma=\alpha \frac{4 v_{r m}}{\sqrt{8 \frac{k}{\theta}}}
$$

In Equation 3, $\alpha$ is a shape parameter characteristic of the pore structure, and is assumed to be equal to 1.7, which corresponds to large spheres with a uniform diameter (Martel et al., 1998).

Foam viscosity cannot be measured with conventional methods because of its dynamic nature. It is therefore necessary to assess the apparent viscosity $\mu_{\text {app }}\left(\mathrm{Pa}_{\mathrm{s}} \mathrm{s}^{-1}\right)$ of foam as it flows in a horizontal 1D porous media using Darcy's Law in its generalized form for the flow of any Newtonian fluid (Bear, 1972; de Marsily, 1986):

$$
\mu_{a p p}=\frac{k \nabla P}{q}
$$

Where $k$ is the intrinsic permeability $\left(\mathrm{m}^{2}\right), \nabla P$ is the pressure gradient $(\mathrm{Pa} / \mathrm{m})$ and $q$ is the volumetric flux $\left(\mathrm{m}^{3} / \mathrm{m}^{2} \cdot \mathrm{s}\right.$ or $\left.\mathrm{m} / \mathrm{s}\right)$. Foam apparent viscosity was calculated by two indirect 
methods (Front velocity and Output methods) as described in the sand column experiments section down below. Foam has been treated as a single phase.

\section{Interfacial tension}

IFTs between surfactant aqueous solutions and p-xylene were measured with a FTA 200 Dynamic Contact Angle Analyzer (First Ten Angstroms, Inc., Portsmouth, Virginia), which uses the pendant drop technique (Woodward, 2000). Images were taken of a p-xylene drop injected upward with a "U" shaped flat ended needle $(0.356 \mathrm{~mm}$ diameter) in a glass cell filled with the tested surfactant at concentrations of $0.01 \%, 0.1 \%$ and $1 \%$. A computer activated pump controlled p-xylene injection. A p-xylene drop needs to be large enough to be distorted by gravity as interfacial tension tries to balance this distortion. IFT was assessed by fitting the shape of the drop to the Young-Laplace equation (Lake, 1989). The captured video image was calibrated with phase densities and with the size of the needle tip. FTA35 software was used to treat drop images and compute IFT values (First Ten Angstroms, Inc., Portsmouth, Virginia).

\subsection{Foam production and injection system}

The foam was produced by alternating injection of surfactant and air at the same pressure in a foam production column. With this method a constant flow of foam was easily produced and foam quality was easily measurable. Foam production at a constant pressure has been reported to be more efficient than production at a constant rate ( $\mathrm{Li}, 2011)$. Other methods were tested but not used, including the injection at a constant rate with syringe pumps and injection with a porous stone in a foam production column. Those methods did not perform well because no foam was produced and only alternate slugs of air and surfactant solution were generated.

A stainless steel tank $(6.6 \mathrm{~L}, 18 \mathrm{~cm}$ diameter, $26 \mathrm{~cm}$ height, $5 \mathrm{~mm}$ thick) was filled with surfactant solution and connected to the pressurized air line controlled by a pressure regulating valve (0.64 cm diameter, 300 psi, Parker) (Figure 2). Then, both air and surfactant solution lines were connected to two valves $(0.5 \mathrm{~cm}$ diameter, shutoff valve $104 \mathrm{R}$, Asco) that opened alternatively at fixed time intervals. This setup allowed air and surfactant solution injection at the same pressure.

Five seconds of surfactant solution injection alternating with ten seconds of air injection were selected for foam production to create a stable injection pressure and to avoid overheating of 
the electric valves with a too short alternate opening. After flowing through the valves, air and surfactant solution are mixed in a T-shaped tube and then go through a foam production column. The foam production column was an acrylic column filled with $2 \mathrm{~mm}$ diameter glass beads with $250 \mu \mathrm{m}$ opening stainless steel screens between each $2.5 \mathrm{~cm}$ glass bead layers. This column allowed the purging of foam until it was found stable and the measurement of its quality before it entered the sand column (Table 2). Foam was flowed through the sand column and filmed at a high resolution with a digital camera (Nikon, Coolpix P510). Four pressure transducers (GP-50, model 311, $\pm 0.5 \%$, InterTechnology, Toronto, Canada) were placed at key positions to measure changes in pressure along the system (Figure 2): one at the foam production column inlet (PT-1), one at the sand column inlet (PT-2), one in the upper (PT-3) and lower (PT-4) ports in the sand column. The line carrying the effluent was placed at a fixed height of $5 \mathrm{~cm}$ above the sand column inlet to maintain a back pressure at the outlet of the column and to avoid the uncontrolled drainage of the column.

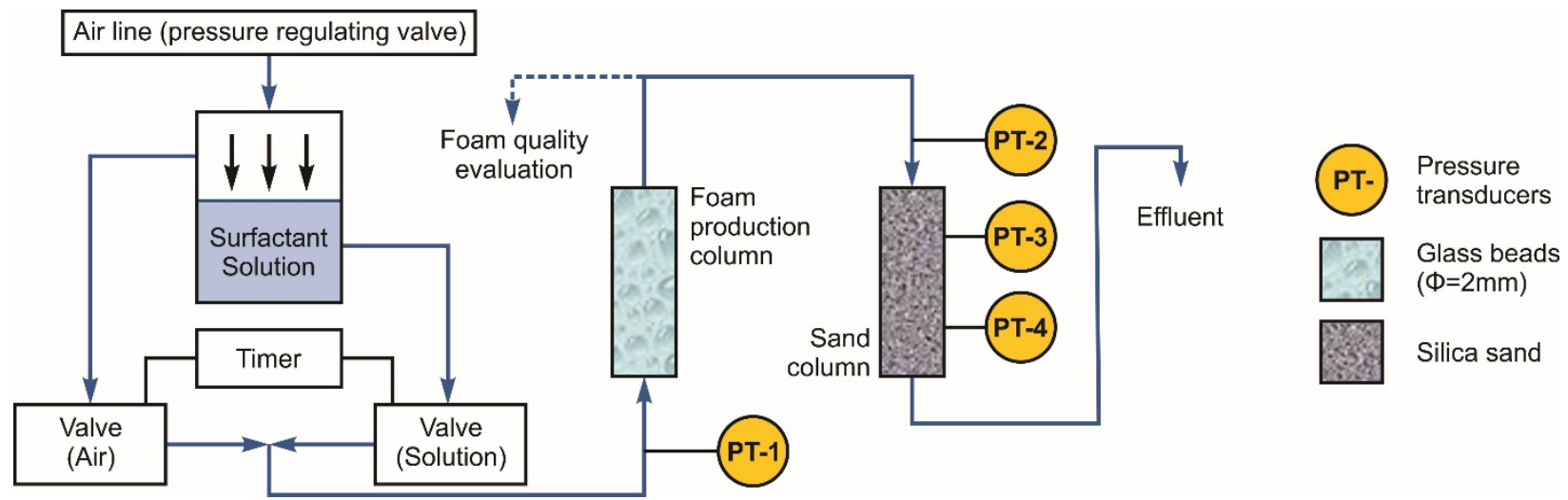

Figure 2 - Experimental setup for foam production and injection into sand column. PT-1 through PT-4 refers to pressure transducers.

\subsection{Sand column experiments}

Sand column experiments are used to assess the suitability of foam for LNAPL remediation. Sand column tests were designed to help understand the effects of different experimental conditions on foam flow through porous medium, especially the use of the foam production column, injection pressure, surfactant concentration, pre-flush liquid prior to foam injection and surfactant types. Sand column experiments were performed with the three most suitable surfactants selected following foamability tests and interfacial tension measurements.

A coarse Temisca 20 (Opta Minerals Inc.) silica sand (99.9\% quartz) having a $d_{10}$ and a $d_{50}$ (grain sizes larger than $10 \%$ and $50 \%$ of sand mass) of 0.75 and $1.3 \mathrm{~mm}$ respectively was used 
for all experiments to minimize fines (clay and silt) and organic matter contents of soils and the interaction of surfactant with other minerals.

Sand filling and compaction in columns were done following the method described by Martel and Gélinas (1996). Columns are made up of a transparent acrylic cylinder with a $3.5 \mathrm{~cm}$ internal diameter and a $14.5 \mathrm{~cm}$ length. Acrylic was selected for its resistance to compression and its transparency, which allowed the filming of foam flow. Both ends are sealed with a perforated Teflon cap combined with a reservoir that uniformly distributes fluids before entry into the sand column. The seal between the acrylic cylinder and the Teflon caps was provided by a Viton O-Ring. A nylon screen (125 $\mu \mathrm{m}$ mesh) in each Teflon cap prevents the loss of sand. Two holes were drilled on the side of the column to connect pressure transducers and the same nylon screen was placed on each hole to prevent sand loss.

Compaction of each $5 \mathrm{~mm}$ sand layer was done by dropping a $500 \mathrm{~g}$ weight 12 times from a height of $8 \mathrm{~cm}$. The top surfaces of compacted layers were lightly scarified to minimize preferential flow paths between subsequent layers. The sand column had a dry bulk density of $1.74 \mathrm{~g} / \mathrm{cm}^{3}$ to prevent channelling (Ripple et al., 1973). Trapped air in the column was eliminated by circulating at least 30 pore volumes of $\mathrm{CO}_{2}$ through the column. Then, the column was saturated from the bottom up with degassed distilled water. At least 3 pore volumes (PV) of water were circulated through the sand column in order to flush or solubilize all $\mathrm{CO}_{2}$. The same column was used for all tests to produce comparable experiments. After each test, the column was rinsed with water and dried with compressed air. It was then purged with $\mathrm{CO}_{2}$ and saturated again with degassed distilled water. Doing so, the column did not have been repacked after each test. With this protocol the sand column used has a hydraulic conductivity to water of $4 \times 10^{-}$ ${ }^{4} \mathrm{~m} / \mathrm{s}$ (permeability of $4 \times 10^{-11} \mathrm{~m} 2$ ), a porosity of 0.34 and a corresponding pore volume of 47 $\mathrm{mL}$.

The impact of the foam production column prior to foam injection in the sand column was evaluated with two column tests: one with a foam production column (Test 1 ) and one without (Test 2). Otherwise, both tests were done under the same conditions (Table 2) and results are shown in figure 5. For the test with the foam production column, a pressurized surfactant solution was first injected in the foam production column, followed by air. The resulting foam was then directed into the sand column connected downstream of the foam production column. In the test without the foam production column, the pressurized surfactant solution was injected directly in the sand column, followed by air. These tests were done to verify if the use of a foam production column before the injection of foam in the sand column would increase the foam 
apparent viscosity. Table 2 summarizes the sand column test conditions. The foam quality at the outlet of the foam production column was about the same ( $86.5 \%)$ for all tested surfactants and was modified following its injection into the sand column (as measured the outlet (Table2)). Note that in this type of injection (SAG) foam quality could vary among other tests conditions depending on slug size and foam formation mechanisms.

In order to be representative of saturated conditions as found in the field, the sand column must be liquid saturated prior to foam injection. The effect of the pre-flush liquid in the sand column prior to foam injection was tested by comparing two alternatives: one using a column preflushed with water (Test 4) and one using a column pre-flushed with surfactant (Test 3), prior to foam injection. Both tests were done under the same surfactant at a concentration of $0.1 \%$ and foam injection pressure of $350 \mathrm{~cm} \mathrm{H} \mathrm{H}_{2} \mathrm{O}$. Results are shown in Figure 6. The effect of surfactant type was evaluated by making three tests, each with a different surfactant solution (Test 1, Test 3 and Test 5) (Table 2). These three tests were done under the same foam injection conditions and the results are presented in Figure 8. Finally, the effect of injection pressure was evaluated by making two tests: one at a lower injection pressure (Test 3) and another at a higher injection pressure (Test 6). Other than injection pressure, both tests were done with the same surfactant and under the same foam injection conditions as shown in Figure 11.

Table 2 - Summary of column tests including the characteristics of each test, a surfactant concentration of $0.1 \% \mathrm{w} / \mathrm{w}$ was used for all sand column tests.

\begin{tabular}{|c|c|c|c|c|c|c|}
\hline $\begin{array}{c}\text { Test } \\
\text { Number }\end{array}$ & $\begin{array}{c}\text { Foam } \\
\text { production } \\
\text { column }\end{array}$ & $\begin{array}{c}\text { Foam quality } \\
\text { outlet of } \\
\text { production } \\
\text { column } \\
\text { (\% air*) }\end{array}$ & $\begin{array}{c}\text { Pre- } \\
\text { flush } \\
\text { liquid* }\end{array}$ & Surfactant & $\begin{array}{c}\text { Foam quality } \\
\text { Injection } \\
\text { pressure } \\
\left.\text { (cm } \mathbf{H}_{\mathbf{2}} \mathbf{O}\right)\end{array}$ & $\begin{array}{c}\text { Futlet of sand } \\
\text { column } \\
\text { (\% air**) }\end{array}$ \\
\hline 1 & Yes & 87.3 & SS & A & 350 & 93.5 \\
\hline 2 & No & - & SS & A & 350 & 59.1 \\
\hline 3 & Yes & 85.5 & SS & B & 350 & 81.3 \\
\hline 4 & Yes & 85.3 & W & B & 350 & 87.7 \\
\hline 5 & Yes & 87.6 & SS & I & 350 & 91.8 \\
\hline 6 & Yes & 86.5 & SS & B & 210 & 90.5 \\
\hline
\end{tabular}

* SS stands for surfactant solution and W for water. ** Foam quality is given as the volume of air over the total effluent volume (\%).

Foam apparent viscosity measurements were done for each column test to evaluate the effect of each distinct experimental condition. Viscosities were estimated via foam flow rate and 
pressure measurements. Injection pressure was maintained constant during each test, Foam flow rates were calculated by two indirect methods: the velocity of the foam front (Front Velocity Method) and the foam flow rate at the system outlet (Output Method). The Front Velocity Method involved the measurement of the foam front velocity when it passed the second pressure transducer in the column. Apparent viscosity was calculated using the pressure gradient between the two pressure transducers (PT-3 and PT-4) in the column at that time. This method provides an evaluation of foam viscosity at the beginning of the column test, before the column is completely swept by foam. The Output Method used foam outflow rate measured at the column outlet after a certain time of foam injection when the pressures measured in the column had stabilized. For this method, apparent viscosity was calculated using the stabilized pressure gradient between the two pressure transducers (PT-3 and PT-4) in the column and the measured flow rate at the column outlet. This method provides a stabilized measurement of foam viscosity just before the experiment ended.

\section{Results}

\subsection{Surfactant selection}

\section{Foamability}

Figure 3 presents foamability indicated by the initial foam height of the Ross Miles Test for all surfactant candidates tested. Surfactants are shown in decreasing order from best to worst foamability at $0.1 \%$ surfactant concentration (red bars). Considering the small changes in foamability between concentrations of $1 \%$ and $0.1 \%$ for the best surfactant candidates and the large impact of surfactant cost on potential future field applications, the concentration used for column testing was fixed at $0.1 \%$. Concentrations of $0.01 \%$ generally produced quite lower foamability and unstable foam that collapsed quickly, so this concentration was thus not considered for further testing. 


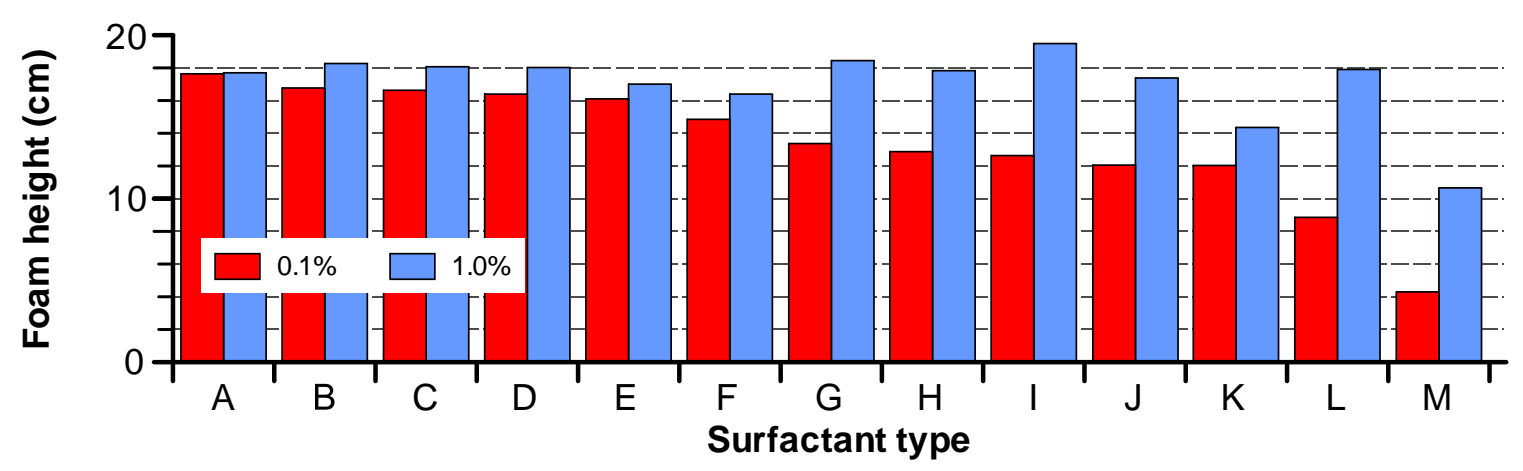

Figure 3 - Foamability of surfactant solution at concentrations of $0.1 \%$ and $1 \%$ w/w measured with the Ross Miles Test for all tested surfactants (A through M; see Table 1). These heights were measured right at the end of the tests (15 min).

\section{Interfacial tension}

Figure 4 shows interfacial tensions between p-xylene and the aqueous surfactant solutions tested. Surfactants were placed in order of increasing interfacial tension at a $0.1 \% \mathrm{w} / \mathrm{w}$ concentration. Surfactant B would provide the best mobilization because it lowers interfacial tension with p-xylene by two orders of magnitude when compared with water $(35 \mathrm{mN} / \mathrm{m})$.

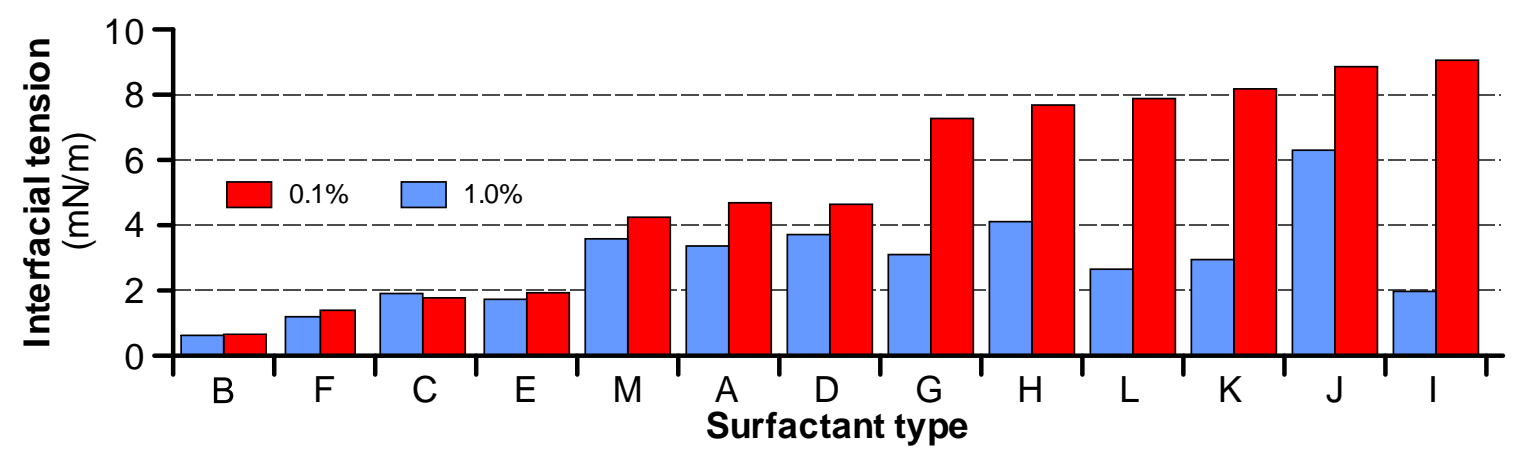

Figure 4 - Interfacial tension between p-xylene and the tested surfactant solutions at concentrations of $0.1 \%$ and $1 \% \mathrm{w} / \mathrm{w}$ (A through $\mathrm{M}$; see Table 1).

Considering the pendant drop and Ross Miles test results, three surfactants $(A, B$, and, $I)$ were selected to be studied in sand column tests (Figure 5, 6 and 8). Surfactant $A$ has the best foamability but has an interfacial tension with p-xylene higher than surfactant B. Surfactant I presents less interesting results in both tests than the other two surfactants and was selected for comparison purposes. Surfactant B was expected to be the best surfactant for p-xylene remediation via foam injection. 


\subsection{Sand column tests to study the effect of various conditions}

\section{Effect of a foam production column on foam stability}

Foam stability during column tests is assessed through visualization of the foam front. A stable front shows a sharp demarcation between the foam- and water-invaded regions in the column. An unstable front shows an indistinct demarcation between the two regions, suggesting the front has collapsed. As foam was injected at the same pressure $(350 \mathrm{~cm}$ water) in both cases, a more viscous foam would result in a lower flow velocity in the column. Relative flow velocity is indicated through the photos of the advancing foam front as shown in Figure 5.

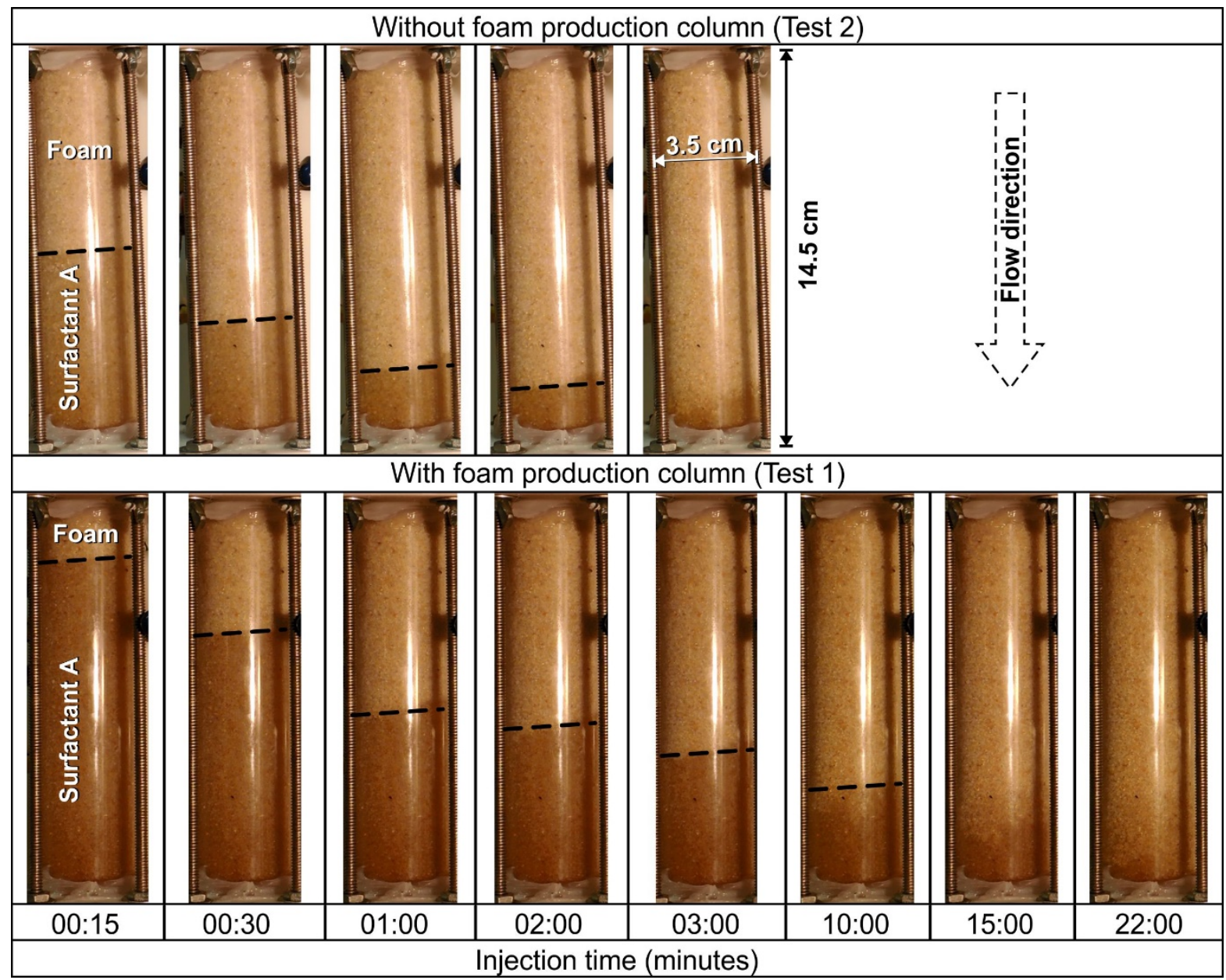

Figure 5 - Advancing foam front of surfactant A (0.1\% w/w concentration) injected downward, following a surfactant pre-flush, at a constant pressure of $350 \mathrm{~cm}$ water in a Temisca 20 sand column with and without a foam production column. The black dotted line indicates the visually observed foam front position (when the front is sharp). 
Figure 5 indicates that the front in the test without a foam production column (top) moved significantly faster than in the test with a foam production column (bottom). This indicates a greater foam viscosity when a foam production column is used. Both experiments showed the formation of a foam with a stable displacement front even if the foam quality is different (a (weak) foam quality of $59.1 \%$ (top) and a strong foam at $93.5 \%$ quality (bottom) at the column outlet (Table 2)). Evaluation of viscosity with the Front Velocity method indicated a value of 8 $\mathrm{mPa} \cdot \mathrm{s}$ without a foam production column, compared with $338 \mathrm{mPa} \cdot \mathrm{s}$ when using one. When the foam front passed the second pressure transducer, it was a lot more viscous in Test 1 than in Test 2. With the Output Method, viscosity estimates were $204 \mathrm{mPa} \cdot \mathrm{s}$ without foam production column and $254 \mathrm{mPa} \cdot \mathrm{s}$ with the foam production column. These results are of the same order of magnitude, thus indicating that when foam has stabilized and pressure is constant, both foam production methods tend to show a similar apparent viscosity.

\section{Effect of water or surfactant pre-flush}

Figure 6 shows that, with a surfactant pre-flush, a straight uniform front is formed. For the water pre-flush experiment, a blurred foam front (made of air) was first formed, resulting in poor sweep, followed by a second front with more viscous foam advancing more slowly with better sweep efficiency. However, both this second, more stable front and the front observed in the surfactant pre-flush experiment took the same time to sweep the column, indicating that foam viscosity was actually similar. For the water pre-flush tests, the apparent viscosity of the foam was evaluated with the Front Velocity Method using the second foam front that was more clearly defined. In fact, the apparent foam viscosities estimated respectively by the Front Velocity or the Output methods were 40 or $44 \mathrm{mPa} \cdot \mathrm{s}$ when water was used as pre-flush fluid and 54 or 59 $\mathrm{mPa} \cdot \mathrm{s}$ when Surfactant B solution $0.1 \%$ was used as pre-flush fluid. 


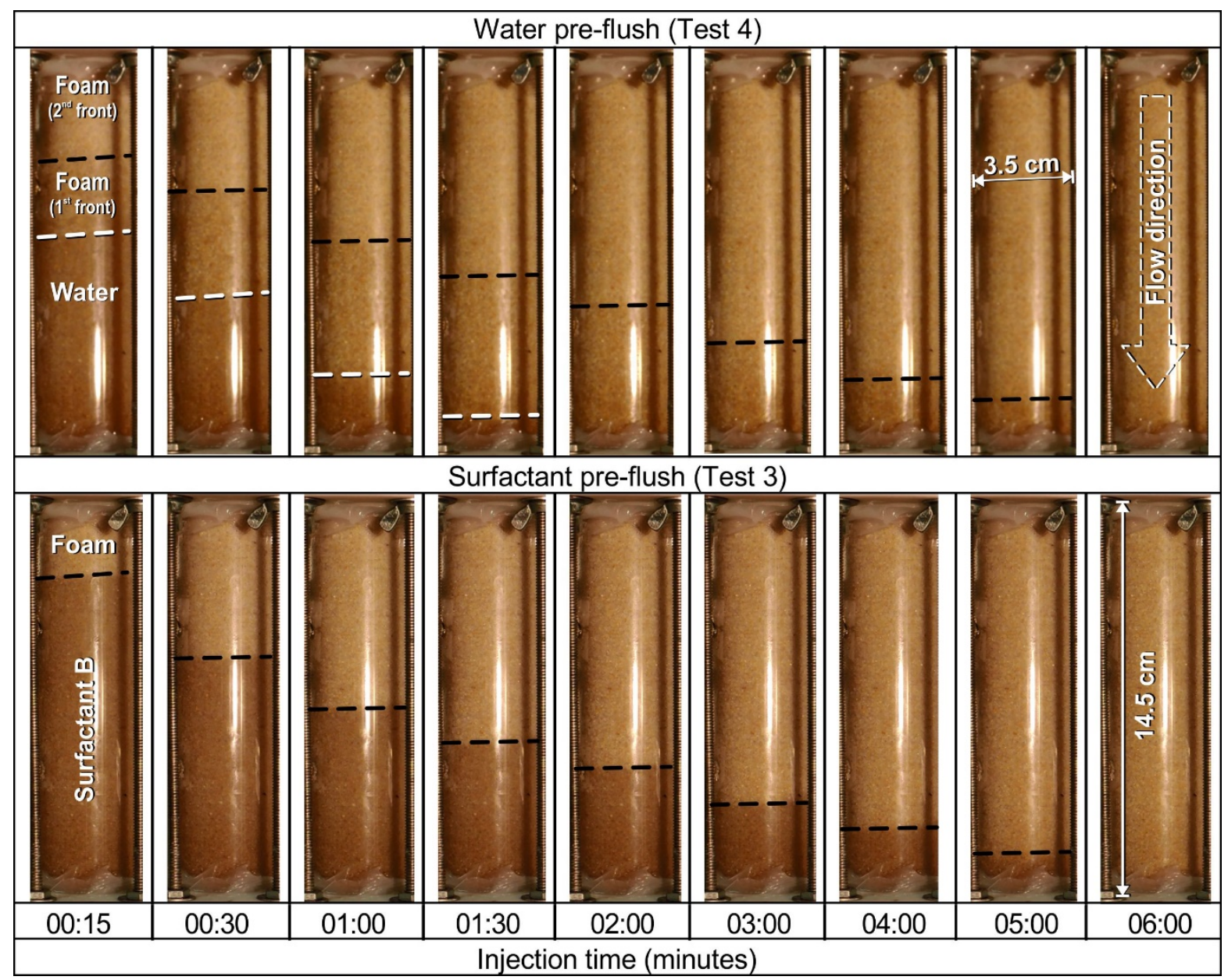

Figure 6 - Advancing foam front of surfactant B injected downward at a pressure of $350 \mathrm{~cm}$ water in the sand column pre-flushed with water or liquid surfactant as a function of time (minutes). The black dotted line indicates the visually observed foam front position (when the front is sharp).

Figure 7 shows the front position through time before reaching the column outlet. The second front with the water pre-flush and the front with the surfactant pre-flush both show similar advancing behavior, which is indicative of similar viscosities. 


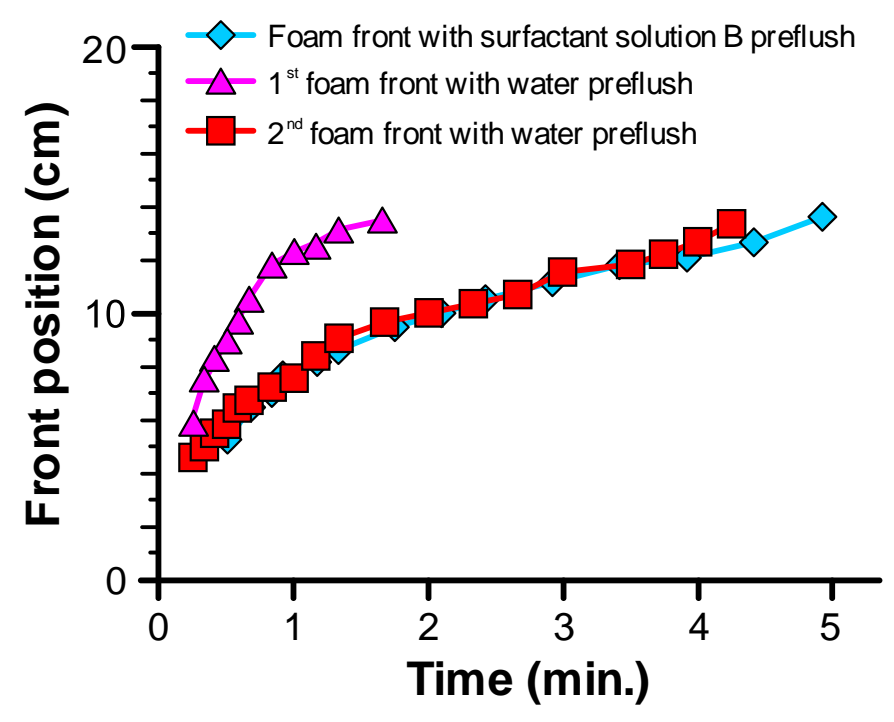

Figure 7- Foam front position of surfactant B $0.1 \%$ w/w foam injected in Temisca 20 sand column preflushed with water or surfactant solution B $0.1 \%$.

\section{Effect of surfactant type}

Figure 8 compares the position of foam fronts for $0.1 \%$ concentrations of surfactants $A$ (Test 1 ), B (Test 3) and I (Test 5) injected at pressures of $350 \mathrm{~cm}$ of water in the sand column. It shows that surfactant I has a foam front moving much faster when compared with the other two; the slowest being surfactant A. Also, the front becomes unstable at the end of foam injection in sand column with surfactant $A$ and $I$.

Figure 9 shows the estimated viscosities of these three foams. Surfactant $A$ is the most viscous and is followed by surfactants B and I. A proportionality between foamability from Ross Miles tests and viscosity calculated during foam injection in water saturated columns was observed (figure 10). Surfactant A produced foam so viscous that the pressure gradient in the column was too high and the front became unstable before the complete sweep of the column (top of Figure 8). Foam viscosity even dropped during the pressure stabilization in the column, which explains the drop between the two calculations of viscosity in Figure 9. 


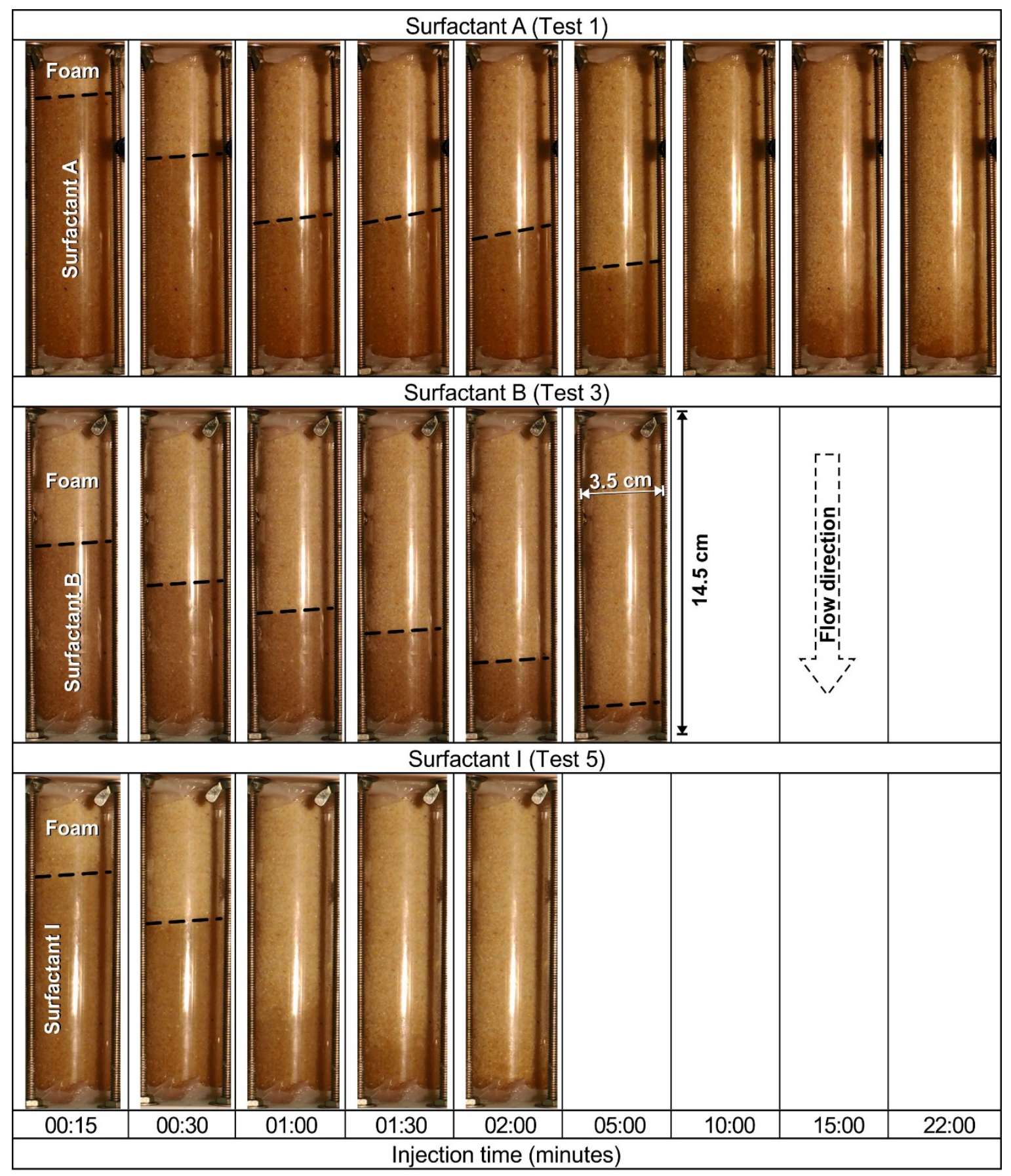

Figure 8 - Advancing foam front of surfactants A, B and I (at a concentration of $0.1 \%$ w/w), after a foam production column, injected downward at a pressure of $350 \mathrm{~cm}$ water in a sand column preflushed with their respective surfactant solution. The black dotted line indicates the visually observed foam front position (when front is sharp). 


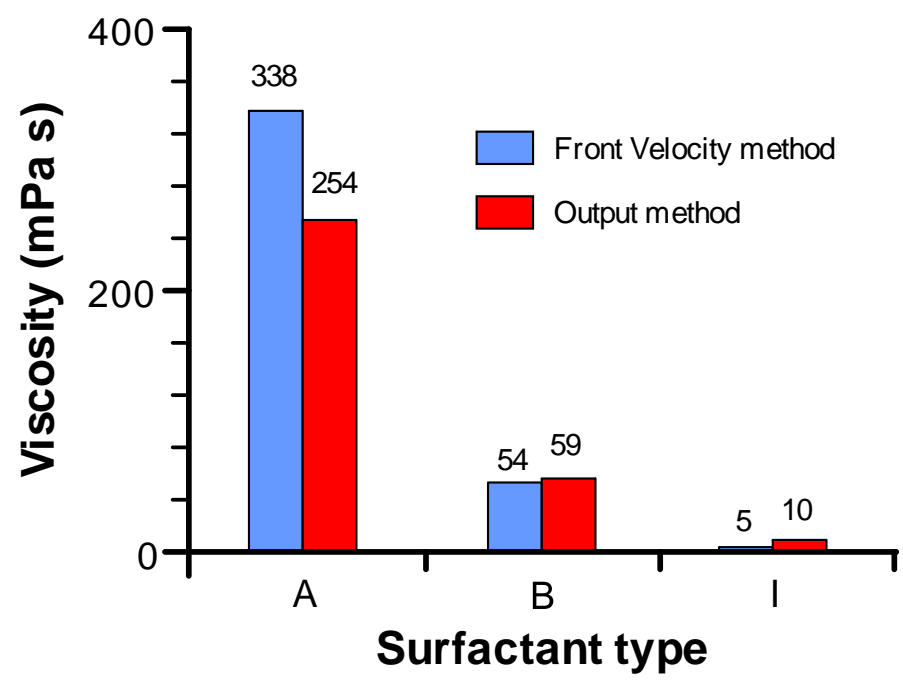

Figure 9 - Calculated foam viscosity in Temisca 20 sand column with surfactants A, B and I foams, as estimated by the Front Velocity and Output methods.

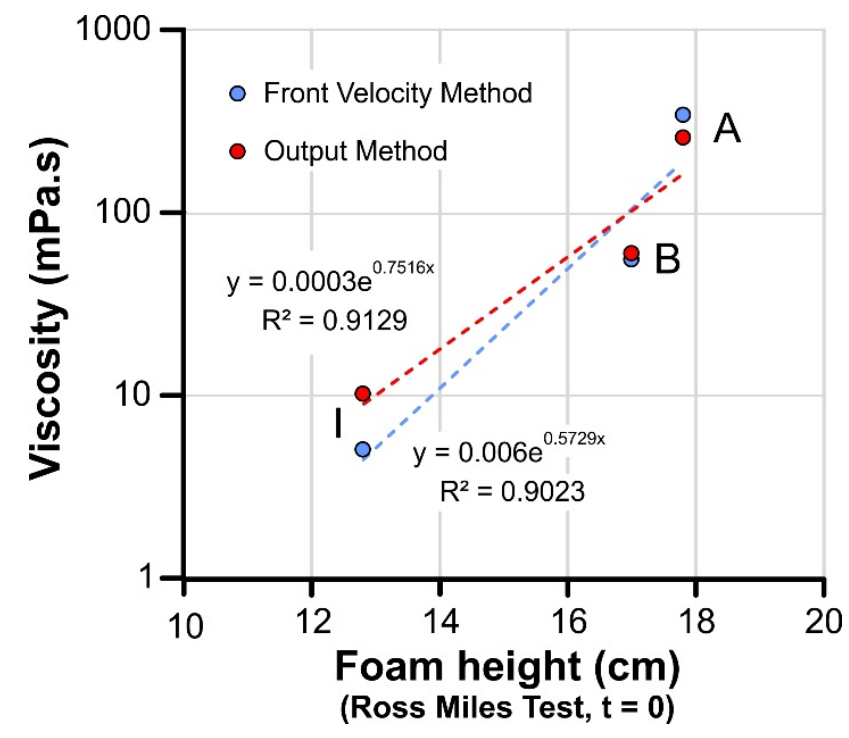

Figure 10 - Correlation between foam height $(\mathrm{cm})$ as evaluated by the Ross Miles tests and foam viscosity in Temisca 20 sand column as estimated by the Front Velocity and Output methods. 


\section{Effect of injection pressure}

Column tests using surfactant $\mathrm{B}$ foam at a concentration of $0.1 \%$ at two different injection pressures: $210 \mathrm{~cm} \mathrm{H}_{2} \mathrm{O}$ (Test 6) and $350 \mathrm{~cm}$ of water (Test 3) were performed. These tests aimed to determine if a lower injection pressure, which would be more suitable under field conditions, could be used without compromising foam front stability and viscosity. An injection pressure of $350 \mathrm{~cm}$ of water produced a significantly more viscous and more stable foam front than injection at $210 \mathrm{~cm}$ of water (Figure 11). Foam viscosities of 54 or $59 \mathrm{mPa} \cdot \mathrm{s}$ at a pressure $350 \mathrm{~cm} \mathrm{H} \mathrm{H}_{2} \mathrm{O}$ and $3 \mathrm{mPa} \cdot \mathrm{s}$ at a pressure of $210 \mathrm{~cm} \mathrm{H}_{2} \mathrm{O}$ were measured in the sand column with Front Velocity or Ouput method.

The Front Velocity Method viscosities of 54 and $3 \mathrm{mP} \cdot \mathrm{s}$ were recorded under shear rates of 109 and $565 \mathrm{~s}^{-1}$ respectively (Equation 3). This confirms that at these injection pressures, the foam exibits a shear-thinning non-Newtonian behavior. 


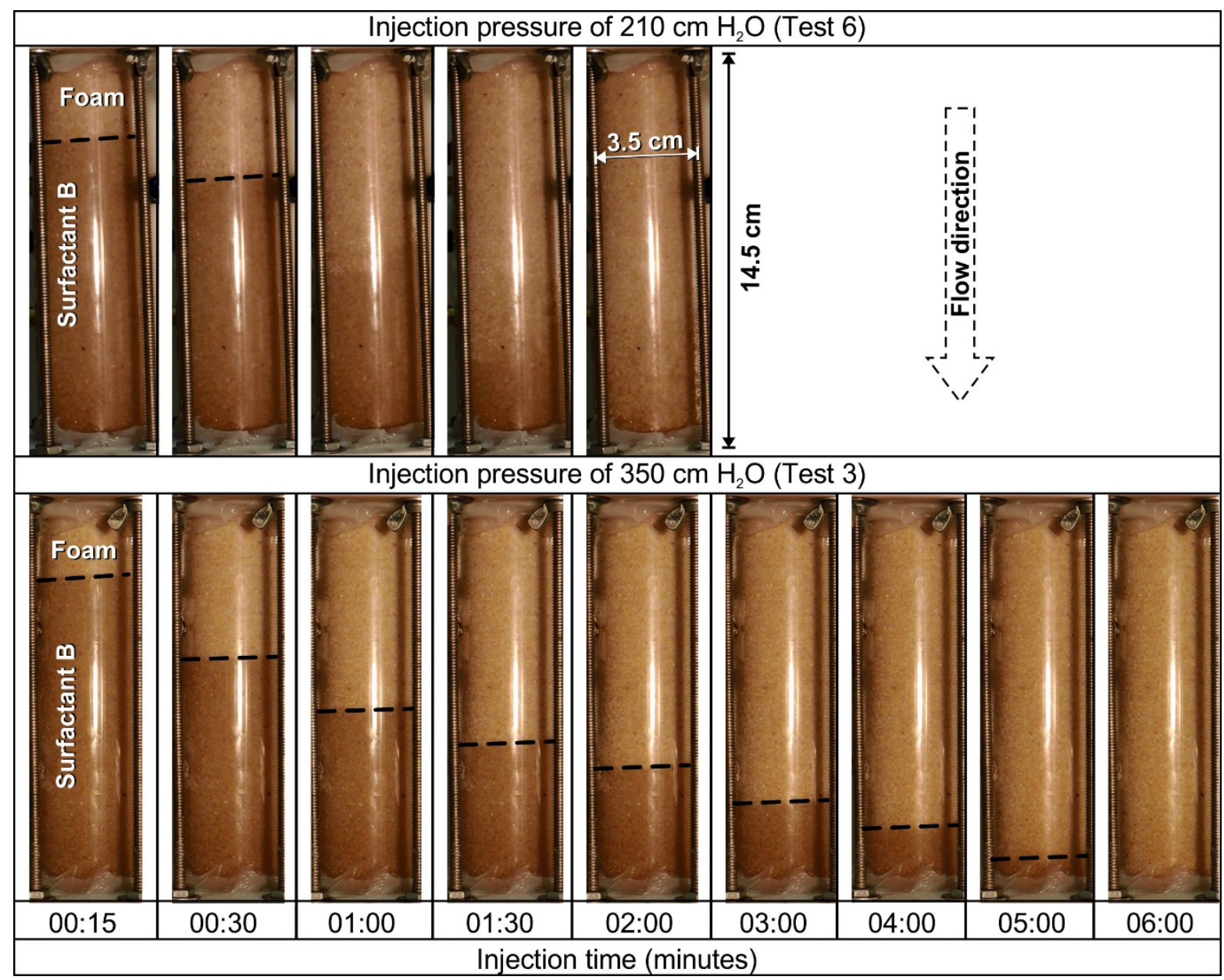

Figure 11 - Advancing foam front of surfactant B $0.1 \% \mathrm{w} / \mathrm{w}$ injected downward at pressures of 210 and $350 \mathrm{~cm}$ water in the sand column pre-flushed with surfactant B solution as a function of time (minutes). The black dotted line indicates the visually observed foam front position (when front is sharp)

\section{Discussion}

For surfactant selection, the Ross Miles Test and the pendant drop technique are two simple and fast methods for the evaluation of surfactant foamability and interfacial tension, respectively. Column test results were in agreement with indications provided by the Ross Miles Test for the three surfactant tested, as the surfactant solution with the best foamability had the most viscous foam front, whereas the one with the worst foamability showed the least viscous foam front. Hence the Ross Miles test results can be used as a screening tool for foam selection. The other foam selection criteria based on the lowering of interfacial tension is not indicative of the behavior of foam when in contact with p-xylene. However, it can be used to maximize the capillary number achieved during the foam flood. Viscous foam provides NAPL displacement and a better sweep efficiency of the porous media via favorable mobility ratio 
(stable displacement), while interfacial tension deacrease allows the contaminant to be drained, moved and recovered easier.

A third foam selection criteria evaluating the direct effect of $p$-xylene on foam would have been nice to have (not performed in this paper) as a selection criteria. This criteria would measure the production and collapse of foam without contact with $p$-xylene and when p-xylene is mixed with surfactant solution prior to foam production therefore quantifying the effect of $p$-xylene on foamability as presented by Simjoo et al. (2012).

Four experimental conditions were tested to evaluate their effect on front stability (Table 3). The best results (i.e. most stable foam front observed) were obtained with the use of a foam production column, surfactant B solution as a pre-flush liquid and as foam and, a high injection pressure (Table 3).

Table 3 - Summary of column test results and conclusions.

\begin{tabular}{|c|c|c|c|}
\hline $\begin{array}{c}\text { Parameter } \\
\text { tested }\end{array}$ & \multicolumn{2}{|c|}{ Regative } & \multirow{2}{*}{ Conclusions } \\
\cline { 2 - 3 } $\begin{array}{c}\text { Effect of } \\
\text { foam } \\
\text { production } \\
\text { column }\end{array}$ & $\begin{array}{c}\text { Without a foam production } \\
\text { column, foam front is blurred and } \\
\text { viscosity is low }\end{array}$ & $\begin{array}{c}\text { With foam production } \\
\text { column, foam front is } \\
\text { sharp and foam } \\
\text { viscosity is high }\end{array}$ & Foam production \\
column is necessary \\
$\begin{array}{c}\text { Pre-flush } \\
\text { liquid }\end{array}$ & $\begin{array}{c}\text { Water pre-flush creates an air } \\
\text { front with poor sweep efficiency } \\
\text { before the foam front }\end{array}$ & $\begin{array}{c}\text { Surfactant pre-flush } \\
\text { creates a sharp and } \\
\text { stable foam front }\end{array}$ & $\begin{array}{c}\text { Surfactant pre-flush } \\
\text { instead of water is } \\
\text { recommended }\end{array}$ \\
\hline $\begin{array}{c}\text { Surfactant } \\
\text { solution }\end{array}$ & $\begin{array}{c}\text { Surfactant A created a highly } \\
\text { viscous foam that was } \\
\text { destabilized at the end of the test } \\
\text { and surfactant I created a front } \\
\text { with very low foam viscosity }\end{array}$ & $\begin{array}{c}\text { Surfactant B created } \\
\text { a sharp and stable } \\
\text { foam front }\end{array}$ & $\begin{array}{c}\text { Surfactant B was } \\
\text { selected }\end{array}$ \\
\hline $\begin{array}{c}\text { Injection } \\
\text { pressure }\end{array}$ & $\begin{array}{c}\text { An injection pressure of } 210 \mathrm{~cm} \\
\text { of water created an unstable } \\
\text { foam front with low foam viscosity }\end{array}$ & $\begin{array}{c}\text { An injection pressure } \\
\text { of } 350 \text { cm of water } \\
\text { created a sharp and } \\
\text { stable foam front }\end{array}$ & $\begin{array}{c}\text { High injection } \\
\text { pressure is } \\
\text { recommended }\end{array}$ \\
\hline
\end{tabular}

The Output Method for foam viscosity measurements required a minimum of $5 \mathrm{~mL}$ of foam and it took on average several minutes to collect this volume. A small flow rate combined with the fact that foam collapses over time made it difficult to obtain accurate measurement of foam flow. When the foam viscosity was very high, with surfactant $A$, the foam flow rate was very low and the measurement of foam flow rate was difficult because not enough foam exited the column. In 
this case, foam flow was underestimated, which increased calculated viscosity. Also, when foam viscosity was very low, with surfactant I, foam tended to collapse faster than with other surfactants. This often produced slugs of air mixed with foam at the column outlet, which could not be monitored or included in foam flow rate measurements. However, those slugs provided clues that this foam had a poor stability. Those considerations indicate that all measurements made with the Output Method underestimated the volume of foam coming out of the column and therefore overestimated foam viscosity.

In this study, an injection pressure as high as $350 \mathrm{~cm}$ of water (0.34 Bar) was required to flood a $14.5 \mathrm{~cm}$ long homogeneous coarse sand column (corresponding to $2.3 \mathrm{bar} / \mathrm{m}$ ) according to the minimal pressure gradients models for strong foam generation considering a prous medium of $40 \mu^{2}$ (Ransohoff and Radke, 1988; Gauglitz et al. 2002 ; Rossen and Gauglitz 1990, Del Campo et al., 2015). More work needs to be done to minimize foam injection pressure and to produce a stable foam front in the porous media, related to the pressure gradient constrain in ER (0.9 bar/m). Also, It means that a higher foam injection pressure would be expected at the field scale in heterogeneous sand having a lower permeability. The use of other gas such as $\mathrm{CO}_{2}$ or $\mathrm{N}_{2}$ instead of air to generate foam, the use of other surfactants or the injection of particles to stabilize the foam are options that may be part of the solution.

\section{Conclusions}

The general objective of this study was to develop a methodology for the selection of a suitable surfactant to make foam for the remediation of LNAPL-contaminated aquifers. Surfactant solutions were tested to compare their foaming properties with the Ross Miles test and their interfacial tension with $\mathrm{p}$-xylene using the Pendant Drop method. Three surfactants solutions were chosen and tested in a homogeneous sand column. Column tests were also done to evaluate injection conditions needed to obtain a stable and viscous foam front: the use of a foam production column, sand column pre-flush with either water or surfactant solution prior to foam injection and injection pressure.

The Ross Miles test proved to be suitable for the identification of surfactant solutions having good foaming properties. Column tests indicated that the surfactant solution with the best foamability in Ross Miles test (Genapol LRO) formed a more viscous foam front during column 
injection compared to the surfactant solution with less foamability (Ammonyx Lo). Also, the surfactant solution with the worst foamability of the three (Tomadol 900) presented an unstable front with very low viscosity. The Ross Miles test being simple and fast, it is an interesting tool to rank surfactant solutions in terms of foaming ability. The other column tests gave indications on conditions to consider for foam injection in further studies: a high injection pressure, the use of a foam production column and the column pre-flush with surfactant solution prior to foam injection.

The tests reported in this study for surfactant selection and foam behavior observed in column are only the first steps towards the field application of surfactant foam injection to remediate LNAPL-contaminated aquifers. Other tests are needed to: (a) evaluate the impact of horizontal injection through soil layers on foam front behavior and, (b) verify the effect of LNAPL on foamability. 


\section{REFERENCES}

Bear, J., 1972: Dynamics of fluids in porous media. Dover Publications, Inc., New York, 764 p.

Chauveteau, G. and Zaitoun, A. 1981. Basic rheological behavior of xnathan polysaccharide solutions in porous media: Effects of pore size and polymer concentration. In: First European Symposium on Enhanced Oil Recovery, Bournemouth, England, 197-214, ed. F.J. Foyers. Elsevier.

Chowdiah, P., Misra, B.R, Kilbane, J.J., Srivastava, V.J., Hayes, T.D., 1998. Foam propagation through soils for enhanced in-situ remediation. J. Hazard. Mater., 62, 265- 280.

Couto, H.J.B., Massarani, G., Biscaia, E.C., Sant'Anna, G.L., 2009. Remediation of sandy soils using surfactant solutions and foams. Journal of Hazardous Materials, 164, 1325-1334.

Del Campo Estrada E., Bertin H. and Atteia O. (2015) Experimental Study of Foam Flow in Sand Columns: Surfactant Choice and Resistance Factor Measurement. Transport in Porous Media 108, 335-354.

Falls, A.H., Musters, J.J., and Ratulowski, J., 1989. The apparent viscosity of foams in homogeneous bead packs. SPE Reservoir Engineering, 155-164.

Farajzadeh, R., Andrianov, A., Hirasaki, G.J., Krastev, R., Rossen, W.R., 2012. Foam-oil interaction in porous media: implications for foam assisted enhanced oil recovery, Adv. Colloid Interface Sci., 183, 1-13.

Gauglitz P. A., Friedmann F., Kam S. I. and Rossen W. R. (2002) Foam generation in homogeneous porous media. Chemical Engineering Science 57, 4037-4052.

Hirasaki, G.J., 1989. The steam-foam process. J. Pet. Technol., 41 (5), 449-456.

Hirasaki, G.J., Jackson, RE., Jin, M., Lawson, J.B., Londergan, J., Meinardus, H., Miller, C.A. et al., 2000. "Field Demonstration of the Surfactant Foam Process for Remediation of a Heterogeneous Aquifer Contaminated with DNAPL," In NAPL Removal: Surfactants, Foams, and Microemulsions, ed. S. Fiorenza, C.A. Miller, C.L. Oubre, and C.H. Ward, Part 1, 3-163. AATDF monograph series, Boca Raton, Florida, USA: Lewis Publishers, CRC Press.

Hirasaki, G.J., Lawson, J.B., 1985. Mechanism of foam flow in porous media: apparent viscosity in smooth capillaries. SPEJ, 25 (2), 176-190.

Jeong, S.W., Corapcioglu, M.Y., Roosevelt, S.E., 2000. Micromodel study of surfactant foam remediation of residual trichloroethylene. Environ. Sci. Technol., 34, 3456-3461.

Jeong, S.W., Corapcioglu, M.Y., 2003. A micromodel analysis of factors influencing NAPL removal by surfactant foam flooding. Journal of Contaminant Hydrology, 60, 77-96.

Jeong, S.W., Corapcioglu, M.Y., 2005. Force analysis and visualization of NAPL removal during surfactant-related floods in a porous medium. Journal of Hazardous Materials, A126, 813

Johnson, P.C., Stanley, C.C., Kemblowski, M.W.,Byers, D.L., Colthart, J.D., 1990. A practical approach to the design, operation, and monitoring of in situ soil-venting systems. Groundwater Monitoring \& Remediation, 10(2), 158-178.

Lake, L. W. (1989) Enhanced oil recovery, Prentice Hall, Englewood Cliffs Inc., New Jersey 07632, USA, $550 \mathrm{p}$ 
Lee $\mathrm{H}$., Heller J., Hoefer A. et al. (1991) Change in apparent viscosity of $\mathrm{CO}_{2}$ foam with rock permeability. SPE reservoir engineering, 6, 421-428.

Lee H. O., Heller J. P. et al. (1990) Laboratory measurements of $\mathrm{CO}_{2}$-foam mobility. SPE Reservoir Engineering, 5, 193-197.

Li, R.F., 2011. Study of foam mobility control in surfactant enhanced oil recovery processes in 1D, heterogeneous 2-D, and micro model systems. PhD Thesis, Rice University, Houston, Texas. $189 \mathrm{p}$.

Li, R.F., Hirasaki, G.J., Miller, C.A., Masalmeh, S.K., 2012a. Wettability alteration and foam mobility control in a layered, 2D heterogeneous sandpack, SPEJ, 17 (4), 1207-1220.

Li, X., Kaeakshev, S.I., Evans, G.M., Stevenson, P., 2012b. Effect of environmental humidity on static foam stability. Langmuir, 28, 4060-4068.

Longpré-Girard, M., R. Martel, T. Robert, R. Lefebvre and J.-M. Lauzon (2016) 2D Sandbox evaluation of foams for mobility control and enhanced LNAPL recovery in layered soils. Journal of Contaminant Hydrology, 193,: 63-73.

Lucy, C. A., \& Tsang, J. S. (2000). Determination of surfactant concentration using micellar enhanced fluorescence and flow injection titration. Talanta, 50(6), 1283-1289.

Maire J. and Fatin-Rouge N. (2017) Surfactant foam flushing for in situ removal of DNAPLs in shallow soils. Journal of hazardous materials 321, 247-255.

de Marsily, G., 1986. Quantitative hydrogeology - Groundwater hydrology for engineers. Academic Press Inc., San Diego, CA.

Mannhardt K., Novosad J., Schramm L. et al. (2000) Comparative evaluation of foam stability to oil. SPE Reservoir Evaluation \& Engineering 3, 23-34.

Martel, R., Gélinas, P.J., 1996. Surfactant solutions developed for NAPL recovery in contaminated aquifers, Groundwater, 34, 143-154.

Martel, R., Hébert, A., Lefebvre, R., Gélinas, P. and U. Gabriel (2004) Displacement and sweep efficiencies observed in a DNAPL recovery test in a contaminated aquifer with washing and polymer solutions injected in a 5-spot pattern , Journal of Contaminant Hydrology, 75,1-29.

Martel, K.E., R. Martel, P.J. Gélinas, and R. Lefebvre. (1998). Laboratory study of polymer solutions used for mobility control during in situ NAPL recovery. Ground Water Monitoring and Remediation, Summer v. 18, no. 3, pp. 103-113.

Mercer, J.W., Cohen, R.M., 1990. A review of immiscible fluids in the subsurface: properties, models, characterization and remediation. Journal of Contaminant Hydrology, 6, 107163.

Mouton, J., Mercier, G., \& Blais, J. F., 2009. Amphoteric surfactants for PAH and lead pollutedsoil treatment using flotation. Water, Air, and Soil Pollution, 197, 381-393.

Mulligan, C.N., Eftekhari, F., 2003. Remediation with surfactant foam of PCP-contaminated soil. Engineering Geology, 70, 269-279.

Nguyen, Q.P., Currie, P.K., Buijse, M., Zitha, P.L.J., 2007. Mapping of foam mobility in porous media. Journal of Petroleum Science and Engineering, 58, 119-132.

Pennell, K.D., Pope, G.A., Abriola, L.W., 1996. Influence of viscous and buoyancy forces on the mobilization of residual tetrachloroethylene during surfactant flooding. Environmental Science and Technology, 30 (4), 1328-1335. 
Portois, C., 2018. Comportement de la mousse en milieu poreux pour confiner une source de pollution: potentialités, contraintes et demonstration en site reel. PhD thesis, Université Bordeaux Montaigne,199 p.

Ransohoff T. and Radke C. (1988) Mechanisms of foam generation in glass-bead packs. SPE reservoir engineering 3, 573-585.

Ripple, C.D., James, R.V., Rubin, J., 1973. Radial particle-size segregation during packing of particle into cylindrical containers. Power Tech., 8, 165-175.

Robert, T., Martel, R. Conrad, S.H. Lefebvre R. and U. Gabriel (2006) Visualization of TCE recovery mechanisms using surfactant-polymer solutions in a two-dimensional heterogeneous sand model .Journal of Contaminant Hydrology, 86, 3-31.

Rossen, W.R., Gauglitz, P.A. (1990) Percolation theory of creation and mobilization of foams in porous media. Am.Inst. Chem. Eng. J.36(8), 1176-1188

Rothmel, R.K., Peters, R.W., St. Martin, E., Deflaun, M.F., 1998. Surfactant foam biodegradation of in situ treatment of TCE DNAPLs. Environ. Sci. Technol., 32, 16671675.

Shalcross, D.C., Castanier, L.M., Brigham, W.E., 1990. Characterization of steam foam surfactants through one-dimensional sandpack experiments. Stanford University Petroleum Research Institute, Stanford, California.

Simjoo, M., Nguyen, Q.P., Zitha, P.L.J., 2012. Rheological Transition during Foam Flow in Porous Media. Ind. Eng. Chem. Res., 51, 10225-10231.

Tanzil, D., Hirasaki, G.J., and Miller, C.A., 2002. Conditions for Foam Generation In Homogeneous Porous Media. SPE 75176.

Woodward, R.P., 2000. Surface Tension Measurements Using the Drop Shape Method. First Ten Angstroms. 8 p. 